\title{
Air quality sensors in public transport stops and cross-system communication
}

\author{
Dan-Marius Mustață ${ }^{1}$ \\ ${ }^{1}$ Faculty of Mechanical Engineering, Politehnica University Timisoara, Romania \\ E-mail: dan.mustata@ student.upt.ro
}

\begin{abstract}
The purpose of this article is to present a state of art implementation of air quality sensors in public transport stops. Effects on health due to different types of pollutants are summarized as well. Functional scope of the solutions, via warning messages displayed for passengers waiting at these stops, including a cross system communication between traffic management and public transport systems, are also focused. Analysis of existing sensor types from multiple view point including functions, types of measured pollutants, price ranges and comparisons are outlined.
\end{abstract}

Keywords: sensors, air quality, pollutants, health, traffic management, public transport

\section{Introduction}

Nowadays, everyone is talking about pollution and the negative effects it has on organic lifeforms.

All countries are aware and try to find solutions for reduction of pollution by means of reducing traffic congestions, or introduction of different types of new engines and ways to power a vehicle. Unfortunately, these new improvement ideas are not planned for the near future, as definitely they need a huge number of financial investments, not mentioning the need in mentality change of the people.

World Health Organization, based on a report from year 2019, presents that only $20 \%$ of the cities world-wide are compliant with air quality standards.[1] Out of all pollutants, the most dangerous and with the highest impact people's health are the Particulate Matter (PM), due to its size, concentration and composition.[1]

Reduction of pollution must follow systemic ways for its implementation, one has to analyze an entire city, area, region. This cannot be done on the fly, from one day to another. Still, as time goes by and until these systemic solutions are implemented and effective solution must be found, offering to the people to benefit of less pollution in congested traffic areas, on a daily basis.

Going to school, to work, to shop, or sightseeing as a tourist, one has to be exposed to health risks, and waste time because of frequent transport malfunctions and associated generated pollution.

Of course, people with personal vehicles do not see this as a major impact, they do not directly feel the pollution level, but still, they all blame the lack of organization and monitoring and the time lost. All experienced waiting in public transport stops during rush hours was a challenge. Traffic congestion, fumes and noises from the passing vehicles are disturbing the wellbeing of the people, not mentioning the lack of information concerning the intensity of the traffic or the expectation time for the next transport opportunity and its potential connections. Of course, pollution is not only associated with traffic, but also due to household systems (especially during winter), local industry, lack of road cleaning and maintenance, unprotected construction sites. In addition, one can mention that there is no clear rule for assessing the transport vehicles, and there is a total incertitude about the number of free chair or 
existing space. Passengers with disabilities, or with luggage or children mostly have no chance to access the public transport. And to top this off, during summer days imagine needing to worry about the ambient temperature as well.

Given these actual situations which are felt by people ongoing to daily business or assuring personal necessities, solutions must be found, which must directly shield them as much as possible from the effects of pollution.

The approach that the author addresses is an informing and warning system by means of which the passengers waiting in public transport stops are correctly and regularly informed directly if certain levels of pollutants (gaseous, solid and noisy) are exceeding the normal ranges, information that would allow them to decide if to stay or to try to move to an area by using different ways (bicycles, electric scooters, etc.) or even walking, or reschedule or postpone the trip. Such system would certainly offer to the passenger notable information about the risks in which he is exposed, the time loss and the impossibility to respect the scheduled initial plan.

Of course, care has to be taken for elderly people, parents with children, groups.

For this, there exists the possibility not only to give a warning but also to give a signal to the urban traffic management system to substitute more public transport vehicles to the respective area.

Traffic management systems already exists, passing currently a needed development and react, as a self-driven responder system. The proposal and subject of this paper is focusing versus the sense that the system can react to main live traffic situations and episodes. For example, in the stops interactive maps could offer alternative route. Or more general the general traffic controller could have an action upon the improvements of the live mode the traffic lights in order to try to reduce congestions.

The following sections will offer an introduction to these new ideas, covering as well the potential systemic solving solutions to be introduced, which can be implemented by using existing functions and control systems of an entire city and coupling them with some new multifunctional devices.

\section{Pollution effects on Human Health}

The negative impact upon the health of human beings, caused by non-proper urban air quality, was recognized already by early and mid-twentieth century, due to a series of severe pollution impact cases. Examples of such can be recognized in Meuse Valley (Belgium, 1930), Donora (USA, 1948) and London (UK, 1952), which clearly lead to negative health effects ranging from headaches and vomiting to even deaths. [2]

According to a series of analyzes of data performed upon these severe episodes, it is more than certain that people with comorbidities related to cardiorespiratory diseases where at most risk, especially the young and elderly. [2]

Many studies led to a conclusion that it exists clearly a relationship between air pollution and health, during medium- or long-term exposure. On the one hand side, use of volunteers exposed to controlled exposures and on the other, epidemiological studies of people admitted to hospitals. [2]

Based on a report from 2002 made by the World Health Organization, it is estimated that 2 percent of mortality caused by cardiorespiratory diseases are due because of air pollution. Unfortunately, due to living conditions and social-economic status developing countries are the most affected. [2]

Analysis of negative health effects has to be done by studies which take into account a multitude of influence factors which are complex; one of the most challenging being factors due to long term exposure to air pollutants. [2]

A series of major effects of different air pollutants on health are presented in the table 1. In this table, one can recognize that all major pollutants are affecting in different ways human health, leading to several diseases associated. 
Table 1 Major health effects of different major air pollutants [3] [7] [8]

\begin{tabular}{|l|l|}
\hline Pollutant & Effect \\
\hline $\mathrm{SO}_{2}$ & Impaired functions of airways and lungs \\
\hline $\begin{array}{l}\mathrm{SPM} \text { (Suspended } \\
\text { (including PM10 } \\
\text { and PM2.5) }\end{array}$ & $\begin{array}{l}\text { Resulted respiratory health problems. Premature death for people with heart } \\
\text { and lung diseases. Nonfatal heart attacks. Irregular heartbeat. }\end{array}$ \\
\hline $\mathrm{NO}_{2}$ & $\begin{array}{l}\text { Increase of bronchial reactivity, lung damages which can be reversible or } \\
\text { irreversible and also effects on the spleen and liver. }\end{array}$ \\
\hline $\mathrm{CO}$ & $\begin{array}{l}\text { Due to the CO being able to bind with hemoglobin, it reduces the oxygen } \\
\text { carrying capacity of blood. Affected are also the brain, heart and muscle. High } \\
\text { vulnerability for developing fetuses. }\end{array}$ \\
\hline $\mathrm{O}_{3}$ & Airways inflammation which reduces lung functions. \\
\hline $\mathrm{Pb}$ & Hemoglobin production, central nervous system and brain functions affected \\
\hline
\end{tabular}

\section{State of art used cases for Air Quality sensors in public transport stops}

In the following section one presents an informal description of such proposed warning systems and the information readout, which could communicate with the entire traffic management system and reduce the potential health risk and waiting time intervals.

\subsection{Pollution warning system for passengers:}

As previously stated, this new application has two functions. The first and minimum is a warning system in live mode shown to the passengers waiting in the public transport stops.

The system can work with existing public transport stops in which one installs principally an array of sensors for detecting different kinds of pollutants.

A considerable range of sensors which are small, mobile and do not need a separate construction to house them are already available on the market. They can directly be installed and coupled together in the existing construction and design of the public transport stops.

So called low-cost sensors (LCS) are shown by the European Commission to offer sustainable solutions, with highest benefit as being able to support an increased spatial coverage when monitoring air quality within a city. [4]

Due to micro-sensor technology available commercially on a broader scale, purchase and use of these LCS's are targeted by both science initiatives and public authorities. [4]

The major target for public authorities is to increase the density within the area of the city of such kind of monitoring. By using LCSs they do not need to rely only on pricey Air Quality Monitoring Stations (AQMS). [4]

Additionally, LCSs can be operator without expert training and use of skilled operators for maintenance and calibration of measuring devices compared to AQMS. [4].
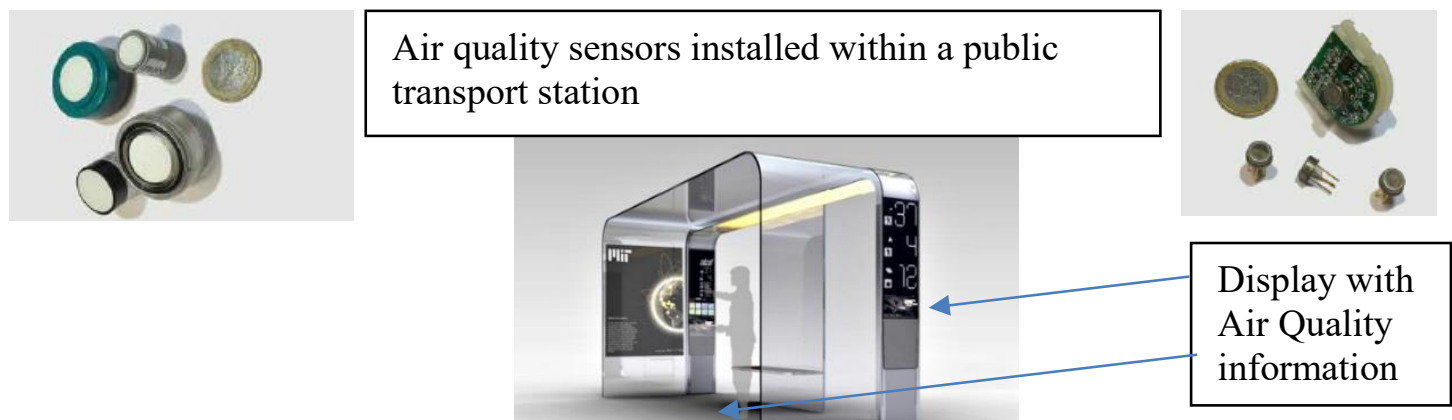

Figure 1 Air quality sensors and warning message displayed on screen 
As shown in figure 1, the system will require installation of such kind of LCS within existing public transport stops. Specific LCS will monitor environmental quality within a specific range and will display the information on a screen installed in the stops. Passengers will be able to read the data in real-time and decide upon whether to stay and wait for the next public transportation vehicle or use alternate ways of transport. Additional information related to traffic conditions can be shown by TMS.

\subsection{Air Quality information readout, communication with traffic management system}

Second function of this application is to communicate with the local or general traffic management system (TMS), already available within the city. TMS receives from all traffic stops such information and can consequently generate an informal map of the pollution level in the area, with the scope to be able also to introduce alarms if necessary, or stopping the traffic- as main polluting source in the area, or deviating it.

Thus, by creating a real time data base with information if upon air quality indices and by comparison to specific limits, different scenarios could be applied. TMS will be able to react in real time and renew the management or adapt it, thus one supposes that in a certain amount of time the entire section of road in that area could be refreshed. By this, traffic congestions or passenger congestions (in the stops or in the vehicles) could be reduced in real-time, resulting in a lower index of pollution in the vicinity of the public transport stops, which will result in reduction of pollutant exposure risk for the passengers.

Even if the cities do not have a TMS in place which is directly controlling and reacting to the flow of traffic, there would be a second functionality.

The system could provide information directly to the Public transport management system (PMPS) allowing thus to react with sending supplementary vehicles directly to the affected area. Passengers will be picked up by a substitute vehicle, sent from the public transport garage directly to the affected area. This vehicle will not pass to each public transport stop like planned for the original vehicle and route, but solve the created traffic jam. Nevertheless, continuous emission control has to follow for the public transport vehicle fleet assuring by this also a safer environment. Preferably, vehicles should be electric powered.

Entire communication logic between public transport stops and multiple systems, as proposed, is presented as a flow chart in figure 2 .

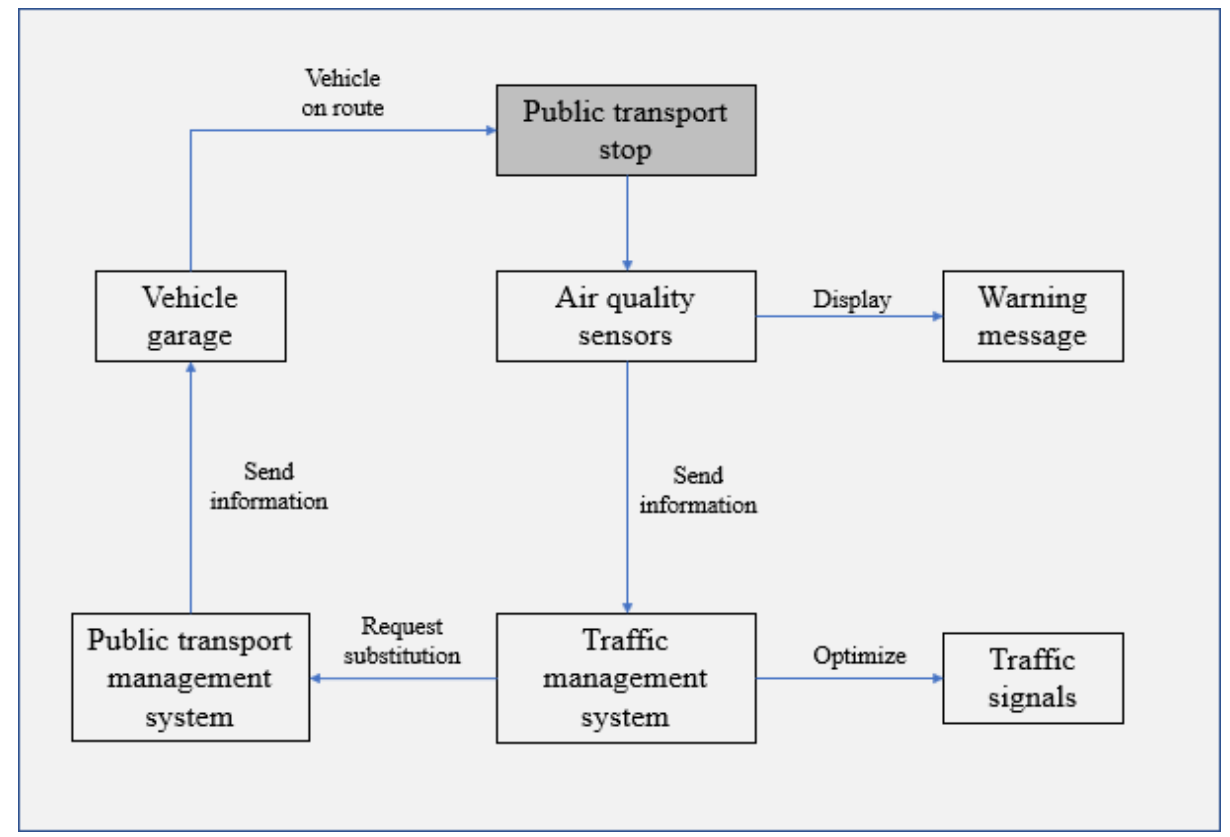

Figure 2 Cross-systems communication flow 


\section{Analysis}

The following section focuses on existing types of LCS, which are already available and affordable on the market as technology used within different applications. A short analysis of minimum required sensor types to be implemented in a public transportation stop is also available.

LCS are of different types and are able to measure different pollutant levels and other parameters as well.

\subsection{Available LCS's and technologies}

Electrochemical sensors, which function based on a chemical reaction between the selected pollutant gas in the air and an electrode placed in a liquid inside a sensor. These sensors types are used to measure concentrations of main species such as $\mathrm{NO}_{2}, \mathrm{SO}_{2}, \mathrm{O}_{3}, \mathrm{NO}, \mathrm{CO}$. Medium cost of purchase (between 50-100€), good measurement resolution, in specific intervals from $\mathrm{mg} / \mathrm{m}^{3}$ up to $\mu \mathrm{g} / \mathrm{m}^{3}$. They are also characterised by a fast response time (between 30-200s). One important downside is the high sensitivity to variation in temperature and humidity of the ambient environment. [5]

Another solution is offered by metal oxide sensors, which are able to react on its surface by modifying its resistance when gases in the air get in contact. They are used to measure $\mathrm{NO}_{2}, \mathrm{O}_{3}, \mathrm{CO}$ concentrations. All are low cost (around 10-15 €/pcs), provide good measurement resolution, similar to that for the electrochemical sensors, but also are affected by temperature and humidity changes. Major disadvantage consists of a long response time $(5-10 \mathrm{~min})$ and a measurement instability which is observable. [5]

Photo Ionization Detectors are measuring volatile organic compounds (VOC) by ionizing VOCs and measuring the output electrical current. They present measurement resolution of $\mathrm{mg} / \mathrm{m}^{3}$, effects due to temperature and humidity changes are limited, very fast response time but they are not able to differentiate between the VOC's, which are ionized. [5]

Optical particle counters are used for the measurement of light scattered by Particulate Matter (PM).They can be purchased at $300 € /$ pcs average price, offer fast response time and high measurement resolution $\left(1 \mu \mathrm{g} / \mathrm{m}^{3}\right)$. The size of the particle is also available as readout (PM10, PM2.5, ...). Disadvantage would be that the sensors compared particle counts to PM mass calculated from theoretical models. [5]

Optical sensors which, by measuring the absorption of infrared light, are able to detect $\mathrm{CO}$ and $\mathrm{CO}_{2}$, could be purchased in the free market from direct producers at prices ranging between 100 and $350 €$, able to measure between 350-2000 ppm $\mathrm{CO}_{2}$. Again, temperature and humidity changes are affecting the measurements. [5]

Programs have been established worldwide for informing the general public about the performance of each low-cost sensor available on the market. Notable program is that developed by the AQ-SPEC (Air Quality Sensor Performance Evaluation Centre) from the USA, which is looking to evaluate performance both in field and under controlled laboratory conditions of LCSs. [6]

\subsection{Minimum required types of LCSs for warning system in public transport stops}

In the opinion of the author based on an analysis of LCS technologies and their advantages and disadvantages, a feasible and minimum option of usage within a public transport stop warning system would be a combination of two sensors, electrochemical plus the optical particle counters.

These two sensors combined will result in measuring a higher range of pollutant than stand-alone LCS $\left(\mathrm{NO}_{2}, \mathrm{SO}_{2}, \mathrm{O}_{3}, \mathrm{NO}, \mathrm{CO}+\mathrm{PM} 10, \mathrm{PM} 2.5\right)$. Price ranges will be around $450 € /$ combination, in total, per public transportation stops which will result in a cheap implementation around the city, or at least around the high traffic congestion areas. Still, a certain level of attention has to be paid for the major disadvantage presented by electrochemical sensors, and corrections must be taken into account. If temperature and humidity levels are prone to constant changes, the measured values might be corrupted. Calibration must be performed on a specific frequency, calculated based on measurement uncertainty, error and standard deviation. 


\section{Conclusion}

Within this article one has presented a potential solution with two different functions (air quality level warning message and cross-system communication between public transport stops, PTMS and TMS), including the comparison of low-cost sensors from cost and effectiveness perspective, bringing a sustainable and cheap implementation project, highlighting the possibility for smarter cities, especially by providing this aforementioned cross-system communication in relation to pollution.

Effects of pollution are recognized and implementation of short-term, and to a certain extent, ideas of such kind are necessary for trying to reduce as much as possible exposure to air pollutant in our daily lives.

The author will focus on further research that will progress in the direction of creating a device that is more complex and complete, which will be able to send real time data cross-systems for correcting traffic conditions in the benefit of general population.

\section{References}

[1] Teriús-Padrón J G, García-Betances R I, Liappas N, Cabrera-Umpiérrez M F, Arredondo

[2] Waldmeyer M T 2019 Design, Development and Initial Validation of a Wearable Particulate Matter Monitoring Solution pp 1, https://doi.org/10.1007/978-3-030-327859_17 (accessed on 10 Feb. 2021)

[3] Metcalfe S, Derwent D 2005 Atmospheric Pollution and Environmental Change pp 84-85, ISBN10: 034071959 1, ISBN-13: 9780340719596

[4] WHO2000 Guidelines for Air Quality. WHO, Geneva pp 32-46, https://apps.who.int/iris/bitstream/handle/10665/66537/WHO_SDE_OEH_00.02eng.pdf? sequence $=18$ \&isAllowed $=y$, accessed on $10^{\text {th }} \mathrm{Feb} .2021$

[5] Karagulian F, Gerboles M, Barbiere M, Kotsev A, Lagler F, Borowiak A 2019 Review of sensors for air quality monitoring pp 2 ISBN 978-92-76-09255-1 ISSN 1831-9424 doi:10.2760/568261,https://publications.jrc.ec.europa.eu/repository/bitstream/JRC116534 /kjna29826enn.pdf, accessed on $10^{\text {th }}$ Feb. 2021

[6] Measuring air pollution with low-cost sensors, Thoughts on the quality of data measured by sensors pp 2-3, https://ec.europa.eu/environment/air/pdf/Brochure\%20lowercost\%20sensors.pdf, accessed on $6^{\text {th }}$ Feb. 2021

[7] http://www.aqmd.gov/aq-spec/home, accessed on $10^{\text {th }}$ Feb. 2021

[8] https://www.epa.gov/pm-pollution/health-and-environmental-effects-particulate-matter-pm, accessed on $10^{\text {th }}$ Feb. 2021

[9] https://www.epa.gov/co-pollution/basic-information-about-carbon-monoxide-co-outdoor-airpollution\#Effects, accessed on $10^{\text {th }}$ Feb. 2021

\section{Acknowledgments}

I would like to express my deep gratitude to Prof. dr. ing. habil Ioana Ionel (Politehnica University Timisoara) for her valuable and constructive suggestions during the planning and development of this article. Her willingness to offer her time and knowledge for guiding me so generously is very much appreciated. I also acknowledge the teacher staff for the ongoing master studies at the mentioned university, especially to senior lecturer dr. ing. Attila Gönczi (Politehnica University Timisoara) 